\title{
EL RENACIMIENTO DEL HUMANISMO EN LAS CIBERCULTURAS: UNA APROXIMACIÓN DESDE EL ARTE
} The Renaissance of humanism in cybercultures: an approach from art

Fernando R. Contreras*

Resumen

Presentamos una recuperación del espíritu humanista en la corriente estética del arte de medios (media art) de las ciberculturas. Para mostrar el giro cultural hacia el neorrenacimiento, hacemos un recorrido por los conceptos que fundan el humanismo clásico y que aproximan el arte contemporáneo a la racionalidad tecnológica y mediática. Este artículo revisa el encuentro del hombre consigo mismo, las subjetividades del arte y la expresión en el paradigma de las nuevas tecnologías, la ciencia y la creatividad, así como la renovación de una emergente epistemología visual que desplaza la concepción moderna de obra de arte, de la figura del artista y del lugar del espectador.

Palabras clave: neorrenacimiento, arte, humanismo, ciberculturas.

Abstract

We present a recovery of the humanistic spirit in the current aesthetics of the media art in the cybercultures. To show the cultural shift towards Neo-Renaissance, we tour the concepts underlying the classical humanism and contemporary art closer to technologic and mediatic rationality. This article reviews the meeting of man with himself, the subjectivities of the Art and the expression in the paradigm of new technologies, science and creativity, as well as the renewal of an emerging visual epistemology that moves the modern concept of the work of art, the figure of the artist and the place of the viewer.

Key words: neorenaissance, art, humanism, cybercultures.

\section{A MODO DE INTRODUCCIÓN}

En este artículo hemos considerado el giro cultural de la posmodernidad y la influencia tecnológica de las ciberculturas en la concepción del arte. Para comprender la complejidad de la transformación estética moderna debemos percibir el cambio de problemática generada por las tecnologías y los medios de comunicación. La obra de arte ya no es única, singular e irrepetible. A diferencia del pasado, la obra mediática nos enfrenta a un nuevo orden estético de las unidades y las series. Las obras del Media Art (arte de medios) creadas con procedimientos técnicos, mediáticos o simplemente, el fenómeno de obras de fabricación seriada por máquinas abren nuevas rutas por los territorios vírgenes de la creatividad. Para el desarrollo de un estudio crítico de esta corriente artística nos ha sido necesario establecer un marco epistémico y teórico que afiance todo cuanto hemos intuido de su observación. Hasta ahora la obra de arte ha sido el objeto de disciplinas como la historia del arte, la teoría del arte y la estética. En 
plena posmodernidad hablamos de la división de nuevos marcos epistémicos; es el caso de los estudios visuales (Brea, 2005) y la revisión de la filosofía del arte (Novitz, 2001). La multiplicación de áreas de trabajo acerca del arte en este comienzo de siglo se debe a la influencia de las tecnologías de la representación, de la expresión y de la comunicación (que dan origen a las ciberculturas) y a la crisis de la modernidad en todos los aspectos del pensamiento occidental. La hipótesis de este estudio tiene en cuenta esta contextura cultural: la obra de arte contemporáneo funda un nuevo modelo estético basado en las máquinas y en la recepción mediada, al tiempo que recupera valores culturales de la herencia antigua, clásica y humanista. A continuación presentamos un estudio que no está basado en la precisa documentación de las obras de arte, ni de su relación o catalogación, no es un análisis minucioso o detallista de la producción artística. Este trabajo de investigación se centra en el interés por hallar unos principios generales de la interpretación del arte contemporáneo y una elaboración sistemática de conceptos descriptivos de la cibercultura.

\section{LA HERENCIA HUMANISTA EN LA CULTURA CONTEMPORÁNEA}

En la investigación más reciente, la cultura se entiende como un proceso que transcurre en el espacio y en un tiempo, más que como un concepto inamovible o una actividad concreta del hombre. Es una consecuencia de la consolidación de la cultura posmoderna (Vattimo, 2000; Connor, 2002; Foster et al., 2006) en la que la obra de arte puede concebirse como algo distinto a una acción definitiva. En este sentido, el arte contemporáneo se exterioriza incompleto y en formación. Bajo estas circunstancias, el conocimiento de la cultura es más complejo que en otros momentos de la humanidad, por ejemplo, en el Renacimiento. Varios factores inciden en la imposibilidad de un consenso respecto de principios fortalecedores de la identidad de una cultura contemporánea: a) la apertura actual de las fronteras entre países en un mundo global; b) la necesidad de alcanzar alianzas políticas para la supervivencia del espíritu civilizado occidental; c) la imposición a la ciudadanía de una Sociedad de la Información cuyas tecnologías generan simulacros de proximidad y de instantaneidad; d) la infiltración de culturas extranjeras desconocidas debido a los actuales movimientos migratorios humanos nos han descubierto un mundo plural diferente; y e) la ruptura con la jerarquía de la autoridad racional representada por las instituciones sociales y artísticas. La falta de acuerdo en los discursos legitimadores del sentido de la cultura ha supuesto el advenimiento de un relativismo cultural, y en consecuencia, un relativismo epistémico, también consecuencia del debilitamiento del pensamiento racionalista en la posmodernidad al considerar otras miradas interculturales de la verdad del mundo.

Nuestras ciberculturas comparten el respeto a la razón o al logos con el humanismo clásico (Grecia y Roma). El pensamiento occidental nace de los primeros pensadores griegos jonios en la costa del Asia Menor (Copleston, 2007, p. 29). Desde entonces la razón y la estética han estado en la fundación de los movimientos artísticos de nuestra cultura. El pensamiento humanista hizo del arte un reducto 
intelectual donde reflexionar acerca de la existencia de los hombres y los diversos debates de la vida: "Pues la herencia clásica constituye una zona de metáforas, un mercado común de símbolos e ideas que trascienden las fronteras tanto de las naciones como de las épocas de una forma que a las literaturas nacionales les resulta imposible" (Gombrich, 2015, p. 79). De este modo, la dialéctica histórica se integró en la naturaleza de la obra de arte que pone en movimiento a la cultura. El espíritu humanista en el arte se desentiende de la idea de los significados inmóviles, los hábitos amarrados y las conductas inquebrantables de los seres humanos en el devenir histórico. Pese a la intención de ruptura constante del arte que el humanismo introduce en la misma naturaleza de la obra, la base del mundo clásico constituye en sí misma una tradición integrada. Esta herencia de conocimientos alcanza nuestra cultura digital desde la interpretación de lo humano, la exégesis de la civilización, el logos, el mito y la mística. Las ciberculturas son estudiadas en las mismas circunstancias que señala Pochat (2008) para el humanismo renacentista, como algo nuevo que empieza desde un punto de referencia: "No obstante, puede hablarse de un nuevo comienzo en lo que se refiere al estudio de la naturaleza, la cosmología y las ciencias asociadas, así como la filología y las ciencias humanas" (199).

Para concretar el significado de las ciberculturas tuvimos que tomar consciencia de su existencia alrededor del individuo y de la colectividad. La herencia clásica nos descubre que en torno a la figura del individuo se consolida la idea de humanidad (humanitas), y sobre ella, la noción de cultura y arte. La concepción humanista de cultura implica varias cuestiones respecto del hombre que también tendrán su interpretación dentro de las ciberculturas: 1) La cultura es la primacía del hombre refinado para la convivencia social y cultural sobre el bárbaro o el salvaje. Hoy hablamos del analfabeto o el bárbaro digital; 2) La cultura es la primacía del hombre refinado que busca el saber por lo que en sí vale. Ahora construimos una sociedad de la información y el conocimiento; 3) La cultura es la primacía de una vida social estabilizada que permite al hombre dedicarse a la reflexión teórica, sobre todo, de la Naturaleza en su conjunto. Actualmente nos relacionamos en redes sociales y comunidades virtuales.

La cultura humanista ofreció dos versiones del mundo mediante el arte y la ciencia. Sus interpretaciones surgirán en las temáticas de los sistemas de representación de la verdad, recreando la vida del individuo y la continuidad de la vida comunitaria. La cultura florecerá a partir de esta dualidad, humanidad y civilización. En este marco de interpretación semiológica la educación (paideia) se concibe como una línea proactiva del desarrollo de la cultura mediante disciplinas orientadas a facultades morales, corporales, políticas e incluso religiosas. Los griegos, como los posmodernos de las ciberculturas, conviven con su tiempo, y su identidad reconocida se forja alrededor de su espíritu científico libre de prejuicios.

La cultura se percibe con un espacio geográfico, organizado socialmente bajo un modelo prototípico, dotada de una tecnología concreta para dominar la naturaleza 
(en la posmodernidad diseñada también en el respeto a la naturaleza) y repleta de relatos con las concepciones del mundo y de la vida expresadas en ideas, formas, estilos, sentimientos y comportamientos por medio de la religión, la literatura, el arte, la filosofía, la ciencia y las formulaciones sociojurídicas.

La instrucción recibida desde la Antigüedad alcanza nuestros días (Antunes, 2002). La realización del valor de la vida, del ideal del mundo y de la misma concepción de hombre surgirá de una civilización del pasado que orienta nuestro pensamiento artístico, cultural y social respecto de las mismas controversias: 1) El progreso. La conversión de un ideal como es el progreso en una ideología como es la racionalidad y ella en un discurso dominante, la ciencia. De este modo, la ciencia (epistémé) y el arte (téchne) se unirán en el mismo propósito de creación de objetos externos al agente (poiésis); 2) La diferencia del hombre con el resto de los animales mediante unas facultades superiores representadas por la poética y por el arte; 3) El valor del arte en los discursos de la consciencia colectiva por vía de la oratoria y de la persuasión, al tiempo que explica su naturaleza histórico-temporal y teleológica (en el sentido de que el arte persigue un itinerario marcado); 4) El arte busca la verdad de la transcendencia de la existencia humana, más allá de las propias subjetividades particulares y de lo inherente de los hechos. La cultura humanista soslaya la valía de las particularidades o las singularidades (como consideraba Aristóteles a la historia) e introduce el valor de los universales.

El arte asumió la autoridad de la racionalidad y de la mente humana (de la inteligencia), para penetrar con éxito en el mundo de los sentidos y atravesar al otro lado, al mundo de lo inconsciente, de los sueños, los deseos, lo arcaico y lo nocturno que brota principalmente de los mitos. En la tradición humanista, es la razón donde reside el ejercicio de la libertad humana, la extrañeza de un mundo exterior material podía ser un impedimento para su libertad a menos que fuese capaz de unificar el pensamiento con ese mundo material. Todos estos valores reviven en la actual cultura.

Michael Podro (2001) elucida que la estética hegeliana plantea dos problemas cuando existe una semejanza entre el pensamiento y el arte: el problema derivado de la función del arte del pasado en la vida mental del presente y el problema del modo en el que el arte se convierte en expresión de la libertad de la mente. Para ello será necesario que el arte elimine cuanto de materialidad posee, así la mente humana no extrañará nada en la obra. Toda la obra en sí nacerá de la propia mente para la mente. El mundo exterior será familiar y lo reconocerá como suyo el discernimiento.

El mundo clásico marcó su impronta en el arte contemporáneo no solo con lo dispuesto por la razón (la visión de lo natural), sino que reconoció la profundidad de la conciencia en la recreación del mundo sobrenatural por medio de los mitos y la mística. 


\section{EL ESPÍRITU DEL HUMANISMO EN LA MODERNIDAD.}

La añoranza de los valores del mundo antiguo estuvo presente en toda la modernidad. Aby Warburg (2005) sentía nostalgia de las formas antiguas, a las que consideraba un elemento central para escribir la historia del arte y un factor indispensable en el florecimiento del pensamiento europeo. Esta civilización se había construido el pasado y era normal que recurriera a ella en la búsqueda de una esencia verdadera latente. La cultura clásica constituía el auténtico legado de la tradición conservada en el arte por la paideia, de siglos de educación. Warburg (2005) se refiere a esta tradición como una memoria supraindividual de imágenes y conocimientos que cada artista podía activar incluso en su significado contrario. Para Michael Podro (2001) "la Antigüedad suministra, por tanto, un material al lenguaje europeo de imágenes, y el arte clásico proporciona un ejemplo supremo de cómo dicho material pudo permanecer bajo control. La cantidad de vocabulario o de control que cada artista o poeta tardíos podrían lograr dependía de su propia mentalidad o de su cultura" (p. 219). La cultura clásica dotará a la modernidad de símbolos con un origen en lo arcaico que expresan sentimientos cuyas raíces se hunden en la complejidad de lo primitivo.

El espíritu iluminista de Kant, junto con las ideas schopenhauerianas y hegelianas, recuperan este antiguo mundo donde la racionalidad en el pensamiento visual desembocará en una tradición autónoma que posee su propio principio de desarrollo. El orden establecido por el mundo clásico mediante la conservación de los cánones universales lo muestra Burckhardt (2004) en su exposición:

Ahora bien, este movimiento de vuelta a la Antigüedad puede decidirse que, en grande y de una manera general y decidida solo se inicia en los italianos con el siglo XIV. Requería un desarrollo de la vida urbana como solo se dio en Italia y solo en este momento: convivencia e igualdad efectiva entre nobles y ciudadanos y constitución de una sociedad general que sintiera la necesidad de la cultura y que dispusiera de tiempo y de medios para satisfacerla. Pero la cultura, al pretender liberarse del mundo fantástico de la Edad Media, no podía llegar, de repente, por simple empirismo, al conocimiento del mundo físico y espiritual. Necesitaba un guía, y como tal se le ofreció la Antigüedad clásica, con su lujo de verdad objetiva y evidente en todas las esferas del espíritu (p. 138-139).

El arte se podrá comprender de este modo desde la transcendencia de las transformaciones de las obras precedentes respecto de las obras del presente. $\mathrm{La}$ visión teleológica de Wölfflin (1978) consistirá precisamente en esto. Con un estudio similar de la evolución estructural de la tragedia de Aristóteles, por su parte Wölfflin afianzará la tesis de que una obra de arte realizada en un género determinado viene a resolver un problema que había surgido previamente.

Konrad Fiedler introduce en el estudio de la fisionomía de la obra clásica de arte la importancia de la construcción social de la mirada. Su perspectiva también aporta algo nuevo: el debate se abría alrededor de la diferencia entre la visión de la 
obra de arte y la visión del mundo cotidiano. Para Fiedler (1990) "la forma que adoptaba el artista era el correlato visual de la evolución del conocimiento conceptual de la filosofia" (Prodo, 2001, p. 148). Es decir, para Fiedler el artista era autónomo respecto de la realidad social que le rodeaba.

En la obra de Wölffin (1978) la herencia de lo clásico es una suma de la revalorización de la realidad social y de la tradición visual. Alrededor del individuo giran aquellos principios artísticos referentes a la clarificación de lo visible y a la simplificación de la apariencia. El ojo humano desea que el objeto expuesto reúna los requisitos que hagan cómoda la imagen de las cosas. La figura humana logrará que el arte introduzca efectivamente el espíritu en la materia.

El extrañamiento del mundo exterior, o la pretensión de que el hombre puede conocerse por su realidad exterior, alcanzará el final de la modernidad llevando a un debate dialéctico las siguientes cuestiones:

1. La incredulidad del hombre frente a los metarrelatos da paso al nihilismo, cuando el poder organizador general en los paradigmas científicos presenta cuestiones irresolubles. Tanto la herencia de los relatos primitivos que fundan nuestra civilización como la ciencia son metarrelatos o metanarraciones, es decir, relatos que supeditan, ordenan y examinan otras narraciones. De modo que cualquier relato local (científico o individual) tiene sentido en cuanto que imita y corrobora el gran relato emancipador de la humanidad en la consecución del espíritu de la autoconsciencia absoluta.

2. En su estudio acerca de la posmodernidad Steven Connor (2002) ha defendido que la ciencia recurre a dos transcripciones del relato legitimador de sentido: una transcripción política de la realidad y otra filosófica. La interpretación política con un origen en el pensamiento ilustrado recoge los ideales de la Revolución Francesa; esencialmente, nos referimos a la emancipación gradual de la humanidad del esclavismo y a la opresión clasista. La versión filosófica presenta a la ciencia como aquello que hace consciente al hombre frente a la inconsciencia ignorante de los problemas. La ciencia (el saber) una vez que es asequible a todos, ayudará a la consecución de la libertad absoluta (p. 9).

3. La falta de confianza en los grandes metarrelatos provoca una crisis de sentido en la cultura occidental. Los relatos universales ya no se centran en la idea del redescubrimiento o el regreso a la verdad originaria. No es la verdad lo que busca el arte (o la ciencia), sino la performatividad o la puesta en escena mediante el simulacro. El arte no persigue la verificación del mundo, sino aquello que funciona mejor en su explicación y que es reducido a las apariencias funcionales de las cosas. La política persuade a los hombres por medio de su estetización que produce discursos atractivos, pero vacíos. Al tiempo, el arte se retira de este ámbito político hastiado de la irrupción de la cultura de masa y de su efecto alienante sobre el espectador. 
La importancia de la apariencia o el simulacro (Baudrillard, 1998) dominará en la búsqueda de la esencia de las cosas, del ser y de los relatos, dando paso a la posmodernidad. En este período de la cultura contemporánea predomina la dimensión estética sobre las disquisiciones del mundo. Esta exaltación estética ha crecido con la industrialización y la tecnificación de la producción cultural. La racionalidad burguesa mantiene un mundo de valor absoluto y autolegitimador por medio del mercado y del modelo de sociedad capitalista. La vanguardia artística denuncia este orden impuesto al arte con la consecuencia de la degradación del kitsch, una obra mercantilizada que reproduce las estructuras industriales de la publicidad y del negocio de la gestión de la cultura.

Durante la modernidad, el mismo espíritu racional de la cultura antigua es utilizado en su propia destrucción. La modernidad es una ruptura continua consigo misma, llevando al arte (como a la ciencia) a su ensimismamiento. Las vanguardias artísticas acaban preguntándose acerca de la singularidad absoluta e independiente y de la unicidad y la autenticidad de la obra de arte verdadera. Pese al declive de la utilidad de estas nociones centrales para la evaluación del arte, persiste el espíritu de lo absoluto y la racionalidad de la innovación que solo valora lo nuevo: "La innovación no consiste en que comparezca algo que estaba escondido, sino en transmutar el valor de lo visto y conocido desde siempre..." (Groys, 2005, p.19). La modernidad se agota en un enfrentamiento dialéctico entre el racionalismo y el irracionalismo, legado manifiesto de dos tradiciones clásicas, la aristotélica y la platónica; y en su final, la modernidad se despide inmersa en un relativismo cultural caótico, pero no por ello menos creativo. La posmodernidad comienza en este punto hacia el redescubrimiento de un arte con una estructura interna clásica y renacentista. En esto último coincidimos plenamente con Wolf Lieser (2009): "No toda representación digital es arte. La frontera es imprecisa, especialmente porque el arte digital combina en gran medida arte, ciencia y tecnología. ¿No recuerda esto a la época del Renacimiento, en la que Leonardo da Vinci, además de artista, era inventor, Miguel Ángel ingeniero y Galileo Galilei, por el contrario, también artista? La simbiosis crea nuevos espacios de pensamiento" (p. 18).

\section{LAS CIBERCULTURAS EN LA POSMODERNIDAD: EL CAMINO DE REGRESO A LO CLÁSICO}

Desde los años sesenta, la cultura experimenta una inflación de los discursos intelectuales, sociales y políticos, consecuencia de la multiplicación de los medios masivos y de las voces de nuevas instituciones (ONG, movimientos sociales, plataformas políticas) e identidades sociales encubiertas por el poder en el pasado (la inmigración, el feminismo, el ecologismo). En el arte de fines del siglo XX el giro lingüístico también supuso otra inversión del arte objetual al arte conceptual (Joseph Kosuth, Robert Barry, Douglas Huebler). En sus obras predomina la superioridad del significado sobre el objeto referencial: el objetivo del lenguaje no es su utilidad para relacionarnos con las cosas de un mundo externo, sino que aspiran a la construcción de mundos propios. Esta misma dirección tomaron los movimientos posteriores como 
Fluxus y la corriente estética del Media Art, por mencionar algunos ejemplos, Joseph Beuys, Nam June Paik o John Cage. Estos creadores venían de ámbitos artísticos diferentes como la literatura, la música, la fotografía, el cine o la performance (entre otros citamos a Philip Glass, Laurie Anderson, David Byrne/Talking Heads, Cindy Sherman, Bill Viola, Shigeko Kubota). El pluralismo mediático de la comunicación, junto con un interés creciente por las tecnologías se sumo al relativismo epistémico posmoderno fundando embrionarias formas interdisciplinares de conocimientos. Además abonan nuevas ideologías, algunas ya citadas anteriormente, que van desde el pacifismo, el feminismo, el ecologismo y más recientes, otras ideologías minoritarias como los movimientos políticos antiglobalización o antisistema. Todos estos factores junto con el entramado de la posmodernidad irán organizando la estructura de las ciberculturas hacia un orden neorrenacentista que describimos concisamente bajo los siguientes garantes de la nueva obra de arte:

1. La influencia de la teoría informacional de Max Bense (1973) y de Abraham Moles (1972) junto con el desarrollo de la informática permitió que a fines de los años sesenta surgiera un gran interés por los gráficos por ordenador. La primera exposición colectiva de computer art comisariada por Jasia Reichardt se tituló Cybernetic Serendipity, en el Institute of Contemporary Art de Londres, entre el 2 de agosto y el 20 de octubre de 1968. La teoría de Bense (1973) formalizó una estética cibernética basada en la optimización de la información mediante estrategias artísticas. La saturación de la información que produce la proliferación de los medios de comunicación provocaron el aburrimiento del público. Las posibilidades de interrelación entre el arte, la ciencia y la tecnología del arte por ordenador se convirtió para Max Bense y sus discípulos Herbert W. Franke, Siegfried Maser y Helmar Frank en la vía de recuperación de la propiedad comunicativa de la obra de arte (Lieser, 2009)

2. Tras la estética cibernética, según Claudia Giannetti (2012, p. 55 y ss.), suceden una estética informacional y una actual estética electrónica. Con la estética informacional, el arte reproduce un modelo de comunicación unidireccional que merma el fundamento estético, dominando una valoración absolutamente racional y numérica (la obra de arte es cuantificada). El valor subjetivo de la experiencia estética desaparece y por el contrario, en este modelo informacional son más importantes los aspectos formales que la misma transmisión de significados. La estética electrónica comienza con los medios digitales e introduce también importantes cambios en la concepción de la obra de arte: a) aporta la figura del espectador activo (en el reemplazo del anterior público pasivo); b) indaga acerca de la naturaleza de la identidad de un hipersujeto planetario, que trasciende la mente individual del sujeto; c) la obra de arte se ordena bajo una estética cinética inspirada en Max Bense (1973) cuando se refería al carácter latente, inerte, inacabado del objeto artístico que ya no se ofrece terminado y concluido por el 
artista; y d) las obras de arte son creaciones compartidas y colectivas que interaccionan con su público modificando su base informacional.

3. El concepto de obra cambia. La modernidad mantenía la fórmula de una obra de arte como un todo simbólico, unitario y sin fracturas. La posmodernidad postestructuralista (Barthes, 2003) considera el texto como un escenario multidimensional, en el que una pluralidad de escritos, ninguno de ellos originales, se desafian y se armonizan. Según ello, Roland Barthes desmitifica la idea de obra maestra o de autor maestro.

4. La concepción de artista también es diferente. El posestructuralismo posmoderno cuestionó la originalidad del artista (o del autor) y la autoridad de la tradición (Foucault, 2010). En un entorno de cultura cocreativa, el autor pierde su valor de experto y la autoría es compartida entre todos. La autoría cede al debate, a la discusión, a las negociaciones y a los acuerdos colectivos en las interpretaciones de la obra de arte.

Durante la posmodernidad, no solo se transforma la autoría del creador, la noción de obra de arte y el lugar del espectador, la propagación de una disposición neoconservadora comienza a recuperar el clasicismo utilizando la experimentación lingüística en la ficción. Por ejemplo elimina la ornamentación barroca y superficial en la literatura y también en la arquitectura con la fundación del estilo internacional (acero y vidrio). El arte experimenta variaciones en todas sus manifestaciones. Las obras de arte han pasado de averiguar la verdad por medio de su representación al modelo del simulacro que se consume en la instantaneidad del ahora y del aquí presente: "Las imágenes actuales se mueven entre el modelo y el referente o entre el documento y la ficción. Sus lugares tienen la extraña consistencia de los sueños o de los mitos, donde los fantasmas de la representación reemplazan la realidad" (Foster et al., 2006, p. 586-587). En esta cuestión hacemos propias las palabras de José Luis Brea cuando vislumbra que el desplazamiento del término "arte" en beneficio del término "visual" supone la pérdida de autorreferencialidad, fundacionalismo y esencialismo (Brea, 2005, p. 62 y ss.). La utilización de la fotografía en el arte consigue presentar la obviedad de las cosas y naturalizar los acontecimientos. Las creaciones adquieren un significado cultural y la mirada del espectador escudriña en qué es lo que las imágenes quieren, es decir, en su influencia social. Las artes parecen estar más cómodas con un mundo mítico, de apariencias, un mundo onírico, de sueños, místico, que reproduce la realidad medinte el simulacro y de su puesta en escena. La teatralidad será la mejor estrategia de la obra de arte buscando ampliar la visión de lo que se entiende por realidad. El espectáculo es el campo de las emergentes formas de poder y de estrategias de subversión, como acabaron demostrando las teorías de los situacionistas (Debord, 2010). El espectáculo desconecta con lo conocido y sorprende la mente del espectador interpretando como real aquello que no lo es. 
El clasicismo resurge en este contexto de la cultura contemporánea por dos razones a nuestro juicio: 1) la oposición a la modernidad y su neobarroquismo (Calabrese, 1994), así como Oswald Spengler (1998) explicaba el Renacimiento como salida de la Edad Media. La cultura clásica en el espíritu de la Antigüedad recuerda el esplendor, la fuerza y la grandeza de Occidente; 2) El redescubrimiento del mundo y del hombre causada por la crítica de la copia de la realidad y de la creación de mundos virtuales. La consciencia del abandono de lo real mediante los simulacros de las máquinas nos lleva a encontrarnos de nuevo con el mundo.

La pérdida del contacto con la naturaleza por medio de su imitación ha sido reemplazado por una idealización de lo particular; lo mismo sucede en el Renacimiento, como ha reparado Götz Pochat (2008, p. 576). El arte indaga sobre sí mismo por vía de la experimentación tecnológica desde sus orígenes, y en esta tarea, no puede más que encontrarse al hombre. El pensamiento abstracto por la introspección de la experiencia estética y la idea de la razón separa al hombre de la realidad objetivada por la ciencia o la historia. El Renacimiento supuso la interposición de esta reflexión científica frente a la superstición y al oscurantismo, contribuyendo a la libertad del hombre. En este comienzo de siglo, surge un paradigma nuevo que fusiona el arte, la ciencia y la tecnología creando sinergias nuevas (como testimonian las obras de los artistas Yves Netzhammer, Gazira Babeli, Ken Goldberg, Alexei Shulgin, Olia Lilalina). Lieser (2009) afirma que "ahora se trabaja sobre la idea de hombre-máquina-mundo-interacción" (p. 244). El arte se considera una cuestión técnica y estética bajo una epistemología de lo visual consistente en la construcción social de la experiencia artística. Esta recuperación del humanismo que denominamos neorrenacimiento (o también "humanismo digital") manifiesta su fe en la experiencia. Esta postura próxima a Aristóteles ya la sostuvo Leonardo da Vinci, como nos recuerda Anthony Blunt (2011): "Todo nuestro saber tiene su origen en nuestras percepciones" (p. 38). El empirismo, las formas ordinarias de la deducción, el desarrollo de leyes generales, el entusiasmo humanista por las matemáticas, la geometría y el estudio de la naturaleza caracterizan tanto el período renacentista como las ciberculturas en la posmodernidad. Las ciberculturas se significan previamente por la intensa influencia de los principios fundadores de la teoría cibernética (autorregulación, comportamientos sistémicos, bucles, autoorganización) enunciada por Norbert Wiener (1998) y por la progresiva concentración de la tecnología digital de la comunicación y la informática en las actividades humanas, incluido el arte. En el Renacimiento como en las ciberculturas la imitación artística es un acto científico y no un simple proceso mecánico. Entre los procesos creadores de este siglo, la modelización digital acabará equiparando el simulacro al fenómeno natural como ha ocurrido en el entrenamiento de los pilotos en los simuladores de vuelo. La ingeniería virtual reproducirá con exactitud lo real, lo que conlleva también su conocimiento profundo. Esta epistemología visual, lejos de idealismos que pueden distorsionar la realidad de la naturaleza, no surge por capricho; 
acercarse al conocimiento del mundo supone volver a redescubrir la figura del hombre. Desde la proporción matemática de lo bello o desde el desequilibrio de la fealdad, las artes renacentistas en la pintura o en la escultura rompen con el modelo absoluto de armonía a favor de reproducir la vida con su dinamismo e individualidad. Las ciberculturas obedecerán a las condiciones de los ordenadores para la construcción de sus realidades virtuales, pero las rivalidades entre artistas y científicos impedirán la instauración de modelos monolíticos. El arte digital abrirá la obra a la continua construcción en la interacción social, con la experimentación científica o supeditándola al descubrimiento científico, aunque tratemos con la ciencia de la mente y la psicología humana del inconsciente (véase la obra de Myron Krueger, Norman White, Jeffrey Shaw, Simon Biggs, Julius von Bismarck).

\section{ALGUNAS CONSIDERACIONES FINALES}

La vuelta al humanismo desde las ciberculturas consiste en una renovación del respeto a la ciencia y a la razón. Para medir la nueva proporción del hombre, el arte recupera el carácter metafísico de las artes, las ciencias (como en el siglo XVI) evolucionan con las máquinas inteligentes y recuperan la armonía divina del espíritu y la libre voluntad humana mediante la ruptura con aquellos principios universales que mecanizaban el alma del hombre. La realidad se convierte en una materia que el artista modela mediante la imaginación, la selección y la idealización. Las tecnologías de las realidades virtuales modifican la visión mediante la transformación psicofísica de los estímulos ópticos. La disputa del arte en el siglo XXI expondrá a los nuevos humanistas a la polémica de las artes liberales digitales. El transformador humanismo supondrá la defensa de un sistema de conceptos sin una filosofía del arte y una teoría estética nueva, más bien como una extensión de la modernidad en la decadencia. El nuevo humanismo si bien contempla una ruptura con un pasado próximo con sus innovaciones digitales, en su interior late el sentimiento de pertenencia a una cultura del pasado.

$\mathrm{El}$ arte contemporáneo ha redescubierto el humanismo en las ciberculturas. En la cultura contemporánea la relación entre arte y razón se mantiene en el paradigma de arte, ciencia y tecnología. Este paradigma puede sintetizarse del modo siguiente: 1) la recuperación del espíritu humanista en las ciberculturas supone la revalorización de la razón y de la estética basada en el conocimiento de la naturaleza y del hombre; 2) la renovación humanista reside en la aceptación de las realidades virtuales; 3) la equiparación de lo real a los mundos artificiales se debe al simulacro creado de la inflación discursiva de las artes de la representación; y 4) la nueva epistemología visual ha modificado la legitimación de la autoría del artista, la concepción de la obra de arte singular y ha desplazado el lugar del espectador de la pasividad a la acción en la posmodernidad y frente a las ciberculturas. 
Universidad de Sevilla*

Facultad de Comunicación

Grupo de Investigación en Tecnología, Arte y Comunicaciónm (PAIDI HUM-868)

Avda. Américo Vespucio, s/n. 41092 Sevilla (España)

fmedina@us.es

\section{OBRAS CITADAS}

Antunes, Manuel. (2002). Teoria da Cultura. Lisboa: Edições Colibri.

Barthes, Roland. (2003). La aventura semiológica. Barcelona: Paidós. Traducción de Ramón Alcalde.

Baudrillard, Jean. (1998). Cultura y simulacro. Barcelona: Kairós. Traducción de Antoni Vicens y Pedro Rovira.

Bense, Max. (1973). Introducción a la estética teórico-informacional: fundamentación y aplicación a la teoría del texto. Madrid: Alberto Corazón. Traducción de Simón Marchán Fiz

Blunt, Anthony. (2011). Teorías de las artes en Italia 1450-1600. Madrid: Cátedra. Traducción José Luis Checa Cremades.

Brea, José Luis. (2005). Estudios visuales. La epistemología de la visualidad en la era de la globalización. Madrid: Akal.

Burckhardt, Jacob. (2004). La cultura del Renacimiento en Italia. Madrid: Edaf. Traducción de Ramón de la Serna y Espina.

Calabrese, Omar. (1994). La era neobarroca. Madrid: Cátedra. Traducción de Anna Giordano.

Connor, Steven. (2002). Cultura Postmoderna. Introducción a las teorías de la contemporaneidad. Madrid: Akal. Traducción de Amaya Bozal.

Copleston, Frederick. (2007). Historia de la Filosofia: 1. Grecia y Roma. Barcelona: Ariel. Traducción de Juan Manuel García de la Mora.

Debord, Guy. (2010). La sociedad del espectáculo. Valencia: Pre-Texto. Traducción de José Luís Pardo.

Fiedler, Konrad. (1990). Escritos sobre el arte. Madrid: Visor. Traducción e introducción de Francisca Pérez Carreño.

Foster, Hal et al. (2006). Arte desde 1900. Modernidad, antimodernidad, postmodernidad. Madrid: Akal. Traducción de Fabián Chueca, Francisco López Martín y Alfredo Brotón Muñoz.

Foucault, Michel. (2010). ¿Qué es un autor?. Córdoba: Ediciones Literarias. Trad. Silvio Mattoni.

Giannetti, Claudia. (2012). Estética Digital. Sintopia da arte, la ciência e tecnologia. Lisboa: Vega.

Gombrich, Ernest H. (2015). Breve historia de la cultura. Barcelona: Península Atalaya. Traducción de Carlos Manzano. 
Groys, Boris. (2005). Sobre lo nuevo. Valencia: Pretextos. Trad. de Manuel Fontán del Junco.

Lieser, Wolf et al. (2009). Arte Digital. Colonia: H.F. Ulmann. Trad. de Kantika Rosés Becker.

Moles, Abraham A. (1972). Théorie de l'information et perception esthétique. Paris: Denoël.

Novitz, David. (2001). The boundaries of art: a philosophical inquiry into the place of art in everyday life. Christchurch, New Zealand: Cybereditions.

Pochat, Götz. (2008). Historia de la estética y la teoría del arte. Madrid: Akal. Traducción de Joaquín Chamarro Mielke.

Podro, Michael. (2001). Los historiadores del arte críticos. Madrid: Antonio Machado Libros. Traducción de Rafael Guardiola.

Spengler, Oswald. (1998). La decadencia de Occidente: bosquejo de una morfología de la Historia Universal. Madrid: Espasa-Calpe. Traducción por Manuel G. Morente.

Vattimo, Gianni. (2000). El fin de la modernidad: nihilismo y hermenéutica en la cultura posmoderna. Barcelona: Gedisa. Traducción de Alberto L. Bixio.

Warburg, Aby. (2005). El renacimiento del paganismo: aportaciones a la historia cultural del Renacimiento europeo. Madrid: Alianza. Edición de Felipe Pereda.

Wiener, Nobert. (1998). Cibernética o el control y la comunicación en animales y máquinas. Barcelona: Tusquets. Traducción de Francisco Martín.

Wölfflin, Heinrich. (1978). Renacimiento y barroco. Barcelona: Paidós. Traducción del equipo editorial de Alberto corazón. 